\title{
Gamma Knife Radiosurgery for Arteriovenous Malformations: Clinical Series of 199 Patients
}

\author{
Ipek ARSLAN ${ }^{1}$, Evrim TEZCANLI ${ }^{2}$, Meltem YILMAZ $^{3}$, Olcay CIZMELI ${ }^{4}$, Meric SENGOZ², Selcuk PEKER ${ }^{5}$ \\ ${ }^{1}$ Gaziosmanpasa University, Department of Radiation Oncology, Tokat, Turkey \\ ${ }^{2}$ Acibadem University, Department of Radiation Oncology, Istanbul, Turkey \\ ${ }^{3}$ Acibadem Kozyatagi Hospital, Department of Radiation Oncology, Istanbul, Turkey \\ ${ }^{4}$ Acibadem University, Department of Radiology, Istanbul, Turkey \\ ${ }^{5}$ Acibadem University, Department of Neurosurgery, Istanbul, Turkey
}

\section{ABSTRACT}

AIM: Cerebral arteriovenous malformations (AVM) are pathological connections between arteries and veins without capillaries. Stereotactic radiosurgery (RS) is a proven and accepted treatment method for cerebral AVMs. Our objective was to analyze the factors influencing the clinical outcome in patients suffering from AVMs.

MATERIAL and METHODS: We retrospectively reviewed 199 patients who were treated with Gamma-Knife RS for intracranial AVMs between 13 October 2005 and 31 October 2010. There were 89 male, 110 female patients with a median age of 32 years (range, 3-74 years). Obliteration was assessed with MRI angiography and DSA imaging.

RESULTS: Complete obliteration rate after RS was $71 \%$ (141 out of 199), including second RS treatments. In terms of obliteration rates, there was no significant difference between patients younger and older than 21 years old $(p=0.669)$. After RS, 3 patients died due to intracranial hemorrhage and 1 died of heart disease. Death from AVM was determined as $1.5 \%$. Intracranial hemorrhage was observed in 7 (3.5 \%) patients post-RS.

CONCLUSION: Obliteration was found to be associated with Spetzler-Martin Grade, Pollock-Flickinger Grade, AVM volume, RS dose, bleeding history before RS and no previous embolization before RS. Gamma knife RS is an effective treatment method for the treatment of AVMs both for pediatric and adult patients. It provides high obliteration and low mortality rates.

KEYWORDS: Arteriovenous malformations, Radiosurgery, Gamma Knife

\section{INTRODUCTION}

$\mathrm{C}$ erebral arteriovenous malformations (AVM) are congenital and benign lesions detected in generally young and healthy individuals. AVMs are pathological connections between arteries and veins without capillaries $(2,8,12,17,21,26,31)$. The prevalence of AVMs in general population is $1.4-4.3 \%(1,11,16,18,29)$, with a spontaneous hemorrhage risk of $2-5 \%$ in untreated AVMs, and $0.7-1 \%$ annual mortality rate $(7,23,42)$. Permanent morbidity risk is $2-3 \%$ and annual mortality risk is $1 \%(8,30)$. Additionally, AVMs may cause headache, seizures and progressive neurological deficits due to ischemia of surrounding brain tissue, with considerable effects on the patient's work activity and quality of life $(8,17,22,30)$.

AVMs can be treated with microsurgery, stereotactic radiosurgery (RS) and endovascular embolization (8). Surgical removal is the initial treatment of choice in appropriate patients as it removes immediate relief from hematoma in ruptured AVMs and decreases the bleeding risk $(3,8,38)$. However, rates of permanent morbidity and mortality related to microsurgery range between $3.9-25 \%$ and $0.7-4.2 \%$, respectively $(3,4,8,12,15,19,20,24,25)$. 
Stereotactic RS is a proven and accepted treatment method for cerebral AVMs $(7,9)$. Indeed, SRS constitutes an important alternative for the treatment of AVMs in surgically inoperable areas with low side effects. Various studies have shown AVM obliteration appears generally in $1-5$ years after RS with 5 year obliteration rates of $70-80 \%(6,7,33,41-43)$.

In this study, effectiveness of RS for the treatment of AVMs and factors affecting the obliteration rate were investigated.

\section{MATERIAL and METHODS}

\section{Patient Characteristics}

We retrospectively reviewed 199 patients who were treated with Gamma-Knife RS for intracranial AVMs in Acibadem University between 13 October 2005 and 31 October 2010. Only patients with a minimum follow-up time of 3 years were enrolled. There were 89 male, 110 female patients with a median age of 32 years (range, 3-74 years).

Gamma Knife RS was applied for patients with unresectable and/or deep brain AVMs in high-risk functional areas, patients who failed to have complete obliteration with endovascular embolization or opted for stereotactic RS instead of surgical resection, patients with residual AVM after surgical resection; patients whose general health status were unsuitable for surgery. The clinical features of these patients are summarized in Table I.

Pre-RS, presenting symptoms were hemorrhage in 86 $(43 \%)$, seizure in $42(21 \%)$, headache in $61(31 \%)$, and other complaints in $9(5 \%)$ patients. Arteriovenous malformation was an incidental finding in $1(0.5 \%)$ patient. Total of 146 of 199 patients $(73 \%)$ were treated primarily by RS (Figure 1AE). Fifty-three patients (27\%) were initially treated before RS as follows; endovascular embolization for 22 patients (11\%) (Figure 2A-C), surgery for 20 patients (10\%), shunt for 4 patients $(2 \%)$, external ventricular drainage (EVD) for 3 patients (2\%), ventriculostomy for 1 patient $(0.5 \%)$, surgery and endovascular embolization for 1 patient $(0.5 \%)$, surgery and RS for 1 patient (0.5\%), endovascular embolization and RS for 1 patient $(0.5 \%) .7$ patients $(3.51 \%)$ had accompanying aneurysm. Twenty-eight patients $(14 \%)$ had neurological deficit prior to RS.

\section{Gamma Knife Radiosurgery Procedure}

All patients underwent stereotactic RS with Leksell Gamma Knife Unit model 4C with 201-Co60 source (A.B. Elekta, Stockholm, Sweden). The treatment procedure began with the positioning of Leksell stereotactic coordinate frame using local anesthesia. Preoperative magnetic resonance imaging (MRI) with contrast and $1 \mathrm{~mm}$ slice thickness was performed. In addition, digital subtraction angiography (DSA) was performed in all patients. Obtained images were transferred to Gamma-Plan treatment planning system. Target volumes were delineated by neurosurgeon and radiation oncologist on MRI and DSA images. Treatment was planned with 4,8 , 14 and $18 \mathrm{~mm}$ collimators using single or multiple shots to ensure target coverage. Plans were then transferred to the treatment machine through network system and treatment was performed with automatic or manual positioning systems. Radiation dose rate changed from $3.42 \mathrm{~Gy} / \mathrm{m}$ to $1.5 \mathrm{~Gy} / \mathrm{m}$ between 2005 and 2010. The median peripheral prescription dose was 22 Gy (range 10-26 Gy) to $50 \%$ isodose in all but 3 patients. The median volume of AVMs was $2.50 \mathrm{cc}$ (range $0.05-39 \mathrm{cc})$. Intravenous prednisone $(10 \mathrm{mg}$ ) was administered 1 hour before and 4 hours after the treatment to avoid brain edema and patients were generally discharged after 4 hours post RS. Previous treatments were considered when deciding the RS dose.

Table I: Patient Characteristics

\begin{tabular}{|c|c|c|}
\hline Patient Number & 199 & \\
\hline \multicolumn{3}{|l|}{ Age } \\
\hline Mean (median) & 33 years & (32 years) \\
\hline Range & 3-74 years & \\
\hline \multicolumn{3}{|l|}{ Follow-up } \\
\hline Mean (median) & 64 months & (60 months) \\
\hline \multirow[t]{2}{*}{ Range } & 7-100 months & \\
\hline & No. of patients & $(\%)$ \\
\hline \multicolumn{3}{|l|}{ Sex } \\
\hline Female & 89 & 45 \\
\hline Male & 110 & 55 \\
\hline \multicolumn{3}{|l|}{ Presentation } \\
\hline Hemorrhage & 86 & 43 \\
\hline Seizure & 42 & 21 \\
\hline Headaches & 61 & 31 \\
\hline Other & 9 & 5 \\
\hline Incidental & 1 & 1 \\
\hline \multicolumn{3}{|l|}{ Neurological deficit } \\
\hline Yes & 28 & 14 \\
\hline No & 171 & 86 \\
\hline Primary RS & 146 & 73 \\
\hline Previous procedures & 53 & 27 \\
\hline Embolisation & 22 & 11 \\
\hline Surgery & 20 & 10 \\
\hline Shunt & 4 & 2 \\
\hline EVD & 3 & 2 \\
\hline Ventriculostomy & 1 & 0.5 \\
\hline Embolisation + RS & 1 & 0.5 \\
\hline Surgery + RS & 1 & 0.5 \\
\hline Surgery + Embolisation & 1 & 0.5 \\
\hline
\end{tabular}




\section{Follow-up Protocol}

Follow-up protocol consisted of clinical examination and MRI at 3, 12, 24 and 36 months and DSA at 3 years after RS. Observation of no flow in MRI or DSA was considered as complete obliteration (CO). In order to confirm obliteration, patients with a $\mathrm{CO}$ at the $\mathrm{MRI}$-angiography were ordered a DSA 3 years after GKRS. However, $23 \%$ of patients refused DSA and underwent cranial MRI follow-up only for the assessment of AVM obliteration. Patients with confirmed CO were then followed-up every 2 years with cranial MRI. Patients with residual lesions after 3 years of initial $R S$ treatment were offered a second RS.

\section{Statistical Methods}

Several parameters including age, gender, AVM grade, AVM volume, treatment dose, previous treatments and performance scores were assessed. Spetzler-Martin and PollockFlickinger 2002 and 2008 classification systems were used for classification $(32,34,39)$ and relationship of these factors with obliteration was investigated.

A Roc analysis was performed in order to analyze the AVM closure at follow-up and to find a cut-off value for AVM volume correlated with AVM obliteration. The date of the DSA or $\mathrm{MRI}$ demonstrating no residual nidus was considered as the date of AVM closure. Predictive factors for AVM nidus obliteration were identified using $T$ test or Mann-Whitney $U$ test. Kolmogorov-Smirnov test was used to assess normality and Chi-square test was used for categorical variables.

For the evaluation of the data obtained in the study, SPSS (Statistical Package for Social Sciences) for Windows 18.0 program was used for statistical analysis. Results were evaluated in $95 \%$ confidence interval and $p<0.05$ was considered to be statistically significant.

\section{RESULTS}

A total of 228 RS treatments were applied to 199 patients. The median follow-up period was 60.2 months (range 7-100.1 months). Total obliteration rate after RS was $71 \%$ (141 out of 199), including second RS treatments. Forty-one patients (20\%) were $\leq 21$ years old and were also evaluated separately as pediatric and young adults group. In terms of obliteration rates, there was no significant difference between patients younger and older than 21 years old $(p=0.67)$. A second $R S$ treatment was applied to a total of 29 patients. In patients where there was a necessity for a second RS because of a residual lesion, median volume of AVM was $4.5 \mathrm{cc}$ (mean 5.6 $\mathrm{cc}$ ) and median dose was 20 Gy during their first RS. The AVM features are summarized in Table II.

Obliteration rate was $56 \%$ (10 patients) for 18 of the 29 patients who underwent second RS with more than 3 years follow-up. No follow-up data is available for 11 patients because their RS treatments were performed more recently.

After RS, 3 of our patients died due to intracranial hemorrhage and 1 died of heart disease. Death from AVM was determined as $1.5 \%$.
Table II: AVM Characteristics

\begin{tabular}{lcc}
\hline & No. of patients & $\%$ \\
\hline Location & & \\
\hline Frontal & 61 & $(31)$ \\
\hline Parietal & 25 & $(13)$ \\
\hline Temporal & 48 & $(24)$ \\
\hline Occipital & 16 & $(8)$ \\
\hline Cerebellar & 9 & $(5)$ \\
\hline Corpus callosum & 5 & $(3)$ \\
\hline Basal ganglia & 10 & $(5)$ \\
\hline Thalamus & 10 & $(5)$ \\
\hline Brainstem & 15 & $(8)$ \\
\hline Concurrent aneurysm & & \\
\hline Yes & 7 & $(4)$ \\
\hline No & 192 & $(96)$ \\
\hline
\end{tabular}

Target volume

\begin{tabular}{lcc}
\hline Range cc & $0.05-39$ & \\
\hline$<4$ cc & 122 & $(61)$ \\
\hline$\geq 4$ cc & 77 & (39) \\
\hline
\end{tabular}

Spetzler-Martin grade

\begin{tabular}{rrr}
\hline I & 16 & $(8)$ \\
\hline II & 45 & $(22)$ \\
\hline III & 119 & $(60)$ \\
\hline IV & 14 & $(7)$ \\
\hline V & 5 & $(3)$
\end{tabular}

Pollock-Flickinger classification 2002

\begin{tabular}{lcc}
\hline Mean & 1.34 \\
\hline Median & 1.18 & \\
\hline Range & 0.29 & -4.90 \\
\hline$<1$ & 74 & $(37)$ \\
\hline $1-1.5$ & 64 & $(32)$ \\
\hline $1.51-2$ & 36 & $(18)$ \\
\hline$>2$ & 25 & $(13)$ \\
\hline Pollock-Flickinger classification 2008 & & \\
\hline Mean & 1.24 & \\
\hline Median & 1.07 & \\
\hline Range & $0.18-4.80$ & \\
\hline$<1$ & 89 & $(45)$ \\
\hline $1-1.5$ & 54 & $(27)$ \\
\hline $1.51-2$ & 35 & $(18)$ \\
\hline$>2$ & 21 & $(11)$ \\
\hline
\end{tabular}



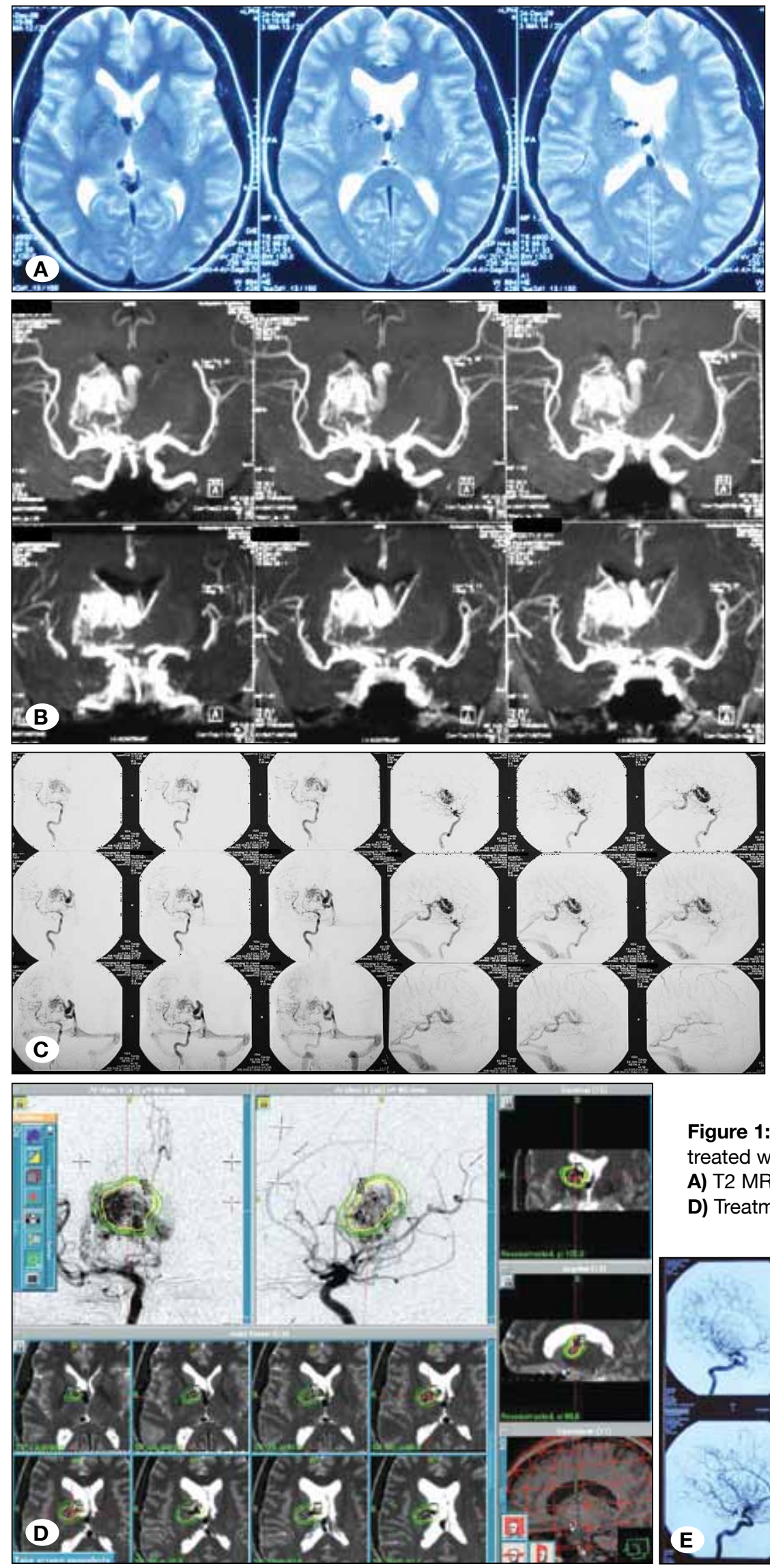

Figure 1: Spetzler-Martin Grade III lesion successfully treated with Gamma Knife radiosurgery.

A) T2 MRI images. B) MR Angiography. C) DSA.

D) Treatment plan. E) Follow-up DSA.

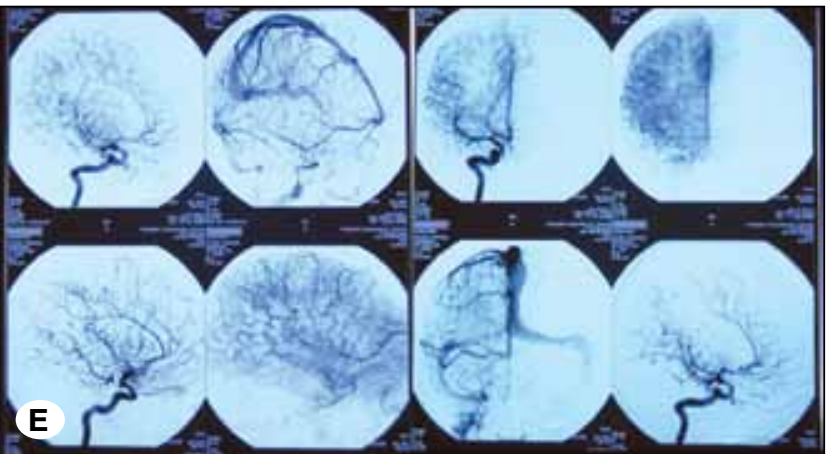


Intracranial hemorrhage was observed in 7 (3.5\%) of the patients post-RS. Median bleeding time after RS was 19.1 months (range 7-48 months). Three of the patients who died as a consequence of bleeding, had experienced intracranial hemorrhage at 7,17 and 34 months post RS, respectively. The AVM volumes of these patients were $14 \mathrm{cc}, 8.2 \mathrm{cc}$ and 30.1 $\mathrm{cc}$, respectively. Staged RS had been planned for the patient with $30.1 \mathrm{cc}$ AVM volume but the patient did not present for the second treatment. Other 3 patients were operated on and their AVM was totally excised. Bleeding after AVM occurred in these patients at 12, 19 and 36 months after RS and their AVM volumes were $3.6 \mathrm{cc}, 1.4 \mathrm{cc}$ and $4.3 \mathrm{cc}$, respectively. A patient who experienced bleeding total of 3 times after RS at $4^{\text {th }}, 5^{\text {th }}$ and $6^{\text {th }}$ years, she underwent shunt surgery and was recommended to undergo second $\mathrm{RS}$, however the patient did not present for retreatment.

Complications were observed after RS treatment in $3(1.5 \%)$ pediatric patients. Existing seizures increased in 1 patient and
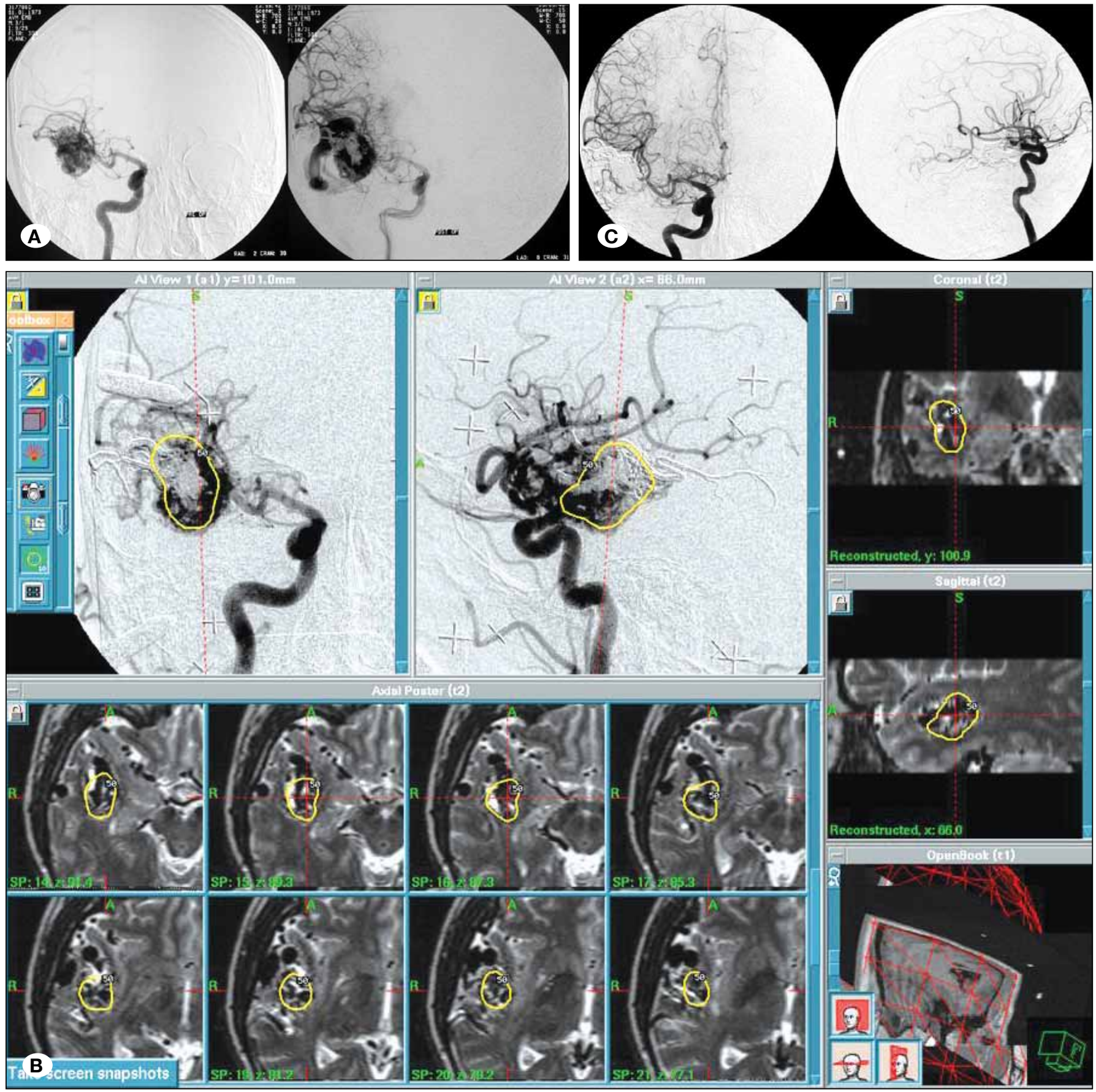

Figure 2: Partially embolized lesion treated with radiosurgery. A) Post-embolization DSA. B) Treatment plan. C) Follow-up DSA. 
seizures appeared in 1 patient after RS treatment, however seizures gradually disappeared in both patients. One patient developed contralateral hemiplegia, it regressed in time but mild motor weakness remained as a sequale. Increase seizures were observed in 7 (3.5\%) adult patients. Total of 13 $(6.5 \%)$ adult patients experienced transient hemihypoesthesia. Headache was observed in $4(2 \%)$ patients and completely regressed with medical treatment. Radiation necrosis was observed in none of the patients. There were transient perinidal T2 changes on MRI in $27 \%$ (54) of the patients after RS.

Obliteration was found to be significantly associated with Spetzler-Martin Grade, Pollock-Flickinger Grade, AVM volume, dose, bleeding history before RS and no previous embolization before RS. Obliteration rate for patients that received $<20$ Gy was $51 \%$ while $77 \%$ for patients who received $\geq 20$ Gy $(p=0.007)$. When lesions were grouped according to their sizes as $0.1-3.5 \mathrm{cc}, 3.51-10.0 \mathrm{cc}$ and $>10 \mathrm{cc}$, obliteration rates were $69 \%, 22 \%$ and $9 \%$, respectively. When lesions with Spetzler Martin Grade 1-3 were compared to those with 4-5, obliteration rates were significantly lower for higher grade lesions; $96 \%$ and $4 \%$, respectively $(p=0.002)$. Obliteration rate was higher $(\mathrm{p}=0.014)$ for patients who presented with bleeding. Obliteration rate was lower $(p=0.007)$ for patients with previous embolization. The correlation between Pollock-Flickinger 2002 classification and obliteration was not significant $(p=0.063)$, however, Pollock-Flickinger 2008 classification was found to be statistically significant $(p=0.006)$.

\section{DISCUSSION}

The main purpose of AVM RS is to ensure total nidus obliteration to avoid future brain hemorrhage and protect the patient from possible side effects. Radiosurgery has been a preferred treatment method with high obliteration and low mortality rates especially for AVMs that are small and in surgically risky areas. Permanent morbidity related to RS is extremely low (0.6-9\%) when compared to surgery. However, AVM RS holds the continuation of hemorrhage risk until the formation of complete AVM obliteration. Annual risk of bleeding even after the obliteration is $0.3 \%$ and annual cumulative risk is $2.2 \%$ (35). So it is deemed necessary to follow the patients even after the angiographically confirmed obliteration, and followup protocols should be designed for long-term management.

Obliteration of the AVM was defined by Lindquist and Steiner in Cerebral Angiography in 1988 as "a normal circulation time, complete absence of pathological vessels in the former nidus malformation, normalization or disappearance of draining veins in the area" (40).

In 1996, Pollock et al. described DSA as the gold standard for determining obliteration, although he suggested the use of $\mathrm{MRI}$, a non-invasive method with which we can also observe the radiation effects on neighboring brain tissue, in patients who refuse DSA (36). We used DSA (77\%) and MRI (23\%) for determining obliteration rates in our patients.

Obliteration rates found in our study $(71 \%)$ was consistent with the previously reported rates of $30-95 \%$ in adult and pediatric cohorts. Although it is suggested that children might respond earlier to RS, in the current study there was no significant difference between the obliteration rates of patients younger and older than 21 years old. Nicolato et al. investigated the difference between children/adolescents and adult patients treated with RS for AVMs (28). They found similar rates of RS-related complications and latency period bleeding in the two populations. In our study, there were similar complication rates after RS for adult and pediatric patients.

Some investigators refuse to treat AVM patients younger than 5 years old with RS to avoid radiation side effects $(27,28,40)$ however we treat these patients and they were also included in this cohort for review. There were no findings of increased side effects or sequale for this age group.

In the current study, intracranial hemorrhage was observed in 7 (3.5\%) of the patients post-RS, all but 1 patient bled during the latency period. Although, some studies found similar natural bleeding rates at any time period after RS, Karlsson et al. and Maruyama et al. found lower rates of hemorrhage after RS during the latency period $(23,37)$.

The most important factor related to the formation of obliteration post AVM RS was marginal radiation dose to the nidus $(5,13,36)$. Higher obliteration rates with higher $\mathrm{RS}$ doses in AVM treatment were reported in many studies. Flickinger et al. mentioned a dose-response curve and reported that doses $\geq 19$ Gy were more effective, however there was no significance in doses >25 Gy (5). In our study, median RS dose was 22 Gy (range 10-26 Gy) and treating with doses $\geq 20$ Gy was found to be significantly correlated with higher obliteration rates.

The current study shows that high rates of AVM obliteration could be achieved with lower doses than previously reported studies. As a result, the similar treatment success could be achieved with a lower incidence of radiation related adverse effects. This is especially important for the pediatric cohort included in our study.

In studies reporting on RS for AVM treatment, AVM volume was found to be related to obliteration. We investigated AVM volume in 3 groups as $0.1-3.5 \mathrm{cc}, 3.51-10.0 \mathrm{cc}$ and $>10$ cc. Obliteration rates in groups were $69 \%, 22 \%$ and $9 \%$, respectively. In other studies, obliteration rates in patients with AVM volume $<10 \mathrm{cc}$ was determined as $74-100 \%$. This rate was $91 \%$ in our study and therefore in line with these rates.

Although, Spetzler-Martin is a grading system developed for the surgical resection, and its suitability for RS is debated, it is frequently used. When lesions with Spetzler-Martin Grade 1-3 were compared to those with 4-5 in our study, obliteration rates were found as $96 \%$ and $4 \%$, respectively. These results indicate that Spetzler-Martin grading system could be a predictor for post-RS obliteration results. Pollock-Flickinger classification system developed in 2002 was not associated with obliteration in our study, while its modified 2008 version was statistically related to obliteration.

Correlated with the literature, obliteration rate in our study was significantly lower for patients with pre-RS embolization (37). In our study, obliteration rate was significantly higher for patients presented with pre-RS intracranial hemorrhage. 
While some studies found correlation between hemorrhage presentation and higher obliteration rates $(10,36)$, Kasliwal et al. suggested no difference in the obliteration rates (14).

Staged RS was planned for 8 patients; however it could be carried out only for 2 . Remaining 6 patients did not present for the planned treatment. One of these patients died of intracranial bleeding at 34 months after RS. Remaining 5 patients still have open AVMs. Compliance factor must be taken into account for the patients planned with staged RS. Large lesions can also be considered for fractionated stereotactic radiotherapy.

\section{CONCLUSION}

Gamma knife RS is an effective treatment method for the treatment of AVMs both for pediatric and adult patients. It provides high obliteration and low mortality rates. In our series, RS dose and AVM volume were found to be related to the success of this treatment method.

\section{REFERENCES}

1. Achrol AS, Guzman R, Varga M, Adler JR, Steinberg GK, Chang SD: Pathogenesis and radiobiology of brain arteriovenous malformations: Implications for risk stratification in natural history and posttreatment course. Neurosurg Focus 26(5):E9, 2009

2. Brown RD Jr, Wiebers DO, Torner JC, O’Fallon WM: Frequency of intracranial hemorrhage as a presenting symptom and subtype analysis: A population-based study of intracranial vascular malformations in Olmsted Country, Minnesota. J Neurosurg 85:29-32, 1996

3. Castel JP, Kantor G: Postoperative morbidity and mortality after microsurgical exclusion of cerebral arteriovenous malformations. Current data and analysis of recent literature. Neurochirurgie 47:369-383, 2001

4. Deruty R, Pelissou-Guyotat I, Mottolese C, Amat D, Bascoulergue Y, Turjman F, Gerard GP: Therapeutic risk in multidisciplinary approach of cerebral arteriovenous malformations. Neurochirurgie 42:35-43, 1996

5. Flickinger JC, Pollock BE, Kondziolka D, Lunsford LD: A doseresponse analysis of arteriovenous malformation obliteration by radiosurgery. Int J Radiat Oncol Biol Phys 36:873-879, 1996

6. Flickinger JC, Kondziolka D, Maitz AH, Lunsford LD: An analysis of the dose-response for arteriovenous malformation radiosurgery and other factors affecting obliteration. Radiother Oncol 63(3):347-354, 2002

7. Fokas E, Henzel M, Wittig A, Grund S, Engenhart-Cabillic $\mathrm{R}$ : Stereotactic radiosurgery of cerebral arteriovenous malformations: Long-term follow-up in 164 patients of a single institution. J Neurol 260(8):2156-2162, 2013

8. Franzin A, Snider S, Boari N, Scomazzoni F, Picozzi P, Spatola G, Gagliardi F, Mortini P: Evaluation of prognostic factors as predictor of AVMS obliteration after Gamma Knife radiosurgery. Acta Neurochirurgica 155(4):619-626, 2013

9. Friedlander RM: Clinical practice. Arteriovenous malformations of the brain. N Engl J Med 356(26):2704-2712, 2007
10. Friedman WA, Blatt DL, Bova FJ, Buatti JM, Mendenhall WM, Kubilis PS: The risk of hemorrhage after radiosurgery for arteriovenous malformations. J Neurosurg 84:912-919, 1996

11. Hernesniemi JA, Dashti $R$, Juvela $S$, Väärt $K$, Niemelä $M$, Laakso A: Natural history of brain arteriovenous malformations: A long-term follow-up study of risk of hemorrhage in 238 patients. Neurosurgery 63:823-831, 2008

12. Hladky JP, Lejeune JP, Blond S, Pruvo JP, Dhellemmes P: Cerebral arteriovenous malformations in children: Report on 62 cases. Childs Nerv Syst 10:328-333, 1994

13. Karlsson B, Lax I, Söderman M: Risk of hemorrhage during the 2-year latency period following gamma knife radiosurgery for arteriovenous malformations. Int J Radiat Oncol Biol Phys 49:1045-1051, 2001

14. Kasliwal MK, Kale SS, Gupta A, Kiran NA, Sharma MS, Agrawal D, Sharma BS, Mahapatra AK: Does hemorrhagic presentation in cerebral arteriovenous malformations affect obliteration rate after gamma knife radiosurgery? Clin Neurol Neurosurg 110(8):804-809, 2008

15. Kenny BG, Hitchcock ER, Kitchen G, Dalton AE, Yates DA, Chavda SV: Stereotactic linac radiosurgery for arteriovenous malformations. J Neurol Neurosurg Psychiatry 55:590-593, 1992

16. Kim H, Sidney S, Mc Culloch CE, Poon KY, Singh V, Johnston SC, Ko NU, Achrol AS, Lawton MT, Higashida RT, Young WL: Racial/ethnic differences in longitudinal risk of intracranial hemorrhage in brain arteriovenous malformation patients. Stroke 38: 2430-2437, 2007

17. Kjellberg RN, Hanamura T, Davis KR, Lyons SL, Adams RD: Bragg-peak proton-beam therapy for arteriovenous malformations of the brain. N Engl J Med 309: 269-274, 1983

18. Koltz MT, Polifka AJ, Saltos A, Slawson RG, Kwok Y, Aldrich EF, Simard JM: Long-term outcome of Gamma Knife stereotactic radiosurgery for arteriovenous malformations graded by the Spetzler-Martin classification. J Neurosurg 118:74-83, 2013

19. Lawton MT, Hamilton MG, Spetzler RF: Multimodality treatment of deep arteriovenous malformations: Thalamus, basal ganglia, and brain stem. Neurosurgery 37:29-35, 1995

20. Lawton MT: Spetzler-Martin Grade III arteriovenous malformations: Surgical results and a modification of the grading scale. Neurosurgery 52:740-749, 2003

21. Loeffler JS, Alexander E 3rd, Siddon RL, Saunders WM, Coleman CN, Winston KR: Stereotactic radiosurgery for intracranial arteriovenous malformations using a standard linear accelerator. Int J Radiat Oncol Biol Phys 17:673-677, 1989

22. Lunsford LD, Kondziolka D, Flickinger JC, Bissonette DJ, Jungreis CA, Maitz AH, Horton JA, Coffey RG: Stereotactic radiosurgery for arteriovenous malformations of the brain. $\mathrm{J}$ Neurosurg 75:512-524, 1991

23. Maruyama K, Kawahara N, Shin M, Tago M, Kishimoto J, Kurita $\mathrm{H}$, Kawamoto S, Morita A, Kirino T: The risk of hemorrhage after radiosurgery for cerebral arteriovenous malformations. N Engl J Med 352(2):146-153, 2005

24. Morgan MK, Johnston IH, Hallinan JM, Weber NC: Complications of surgery for arteriovenous malformations of the brain. J Neurosurg 78:176-182, 1993 
25. Morgan MK, Sekhon LH, Finfer S, Grinnell V: Delayed neurological deterioration following resection of arteriovenous malformations of the brain. J Neurosurg 90: 695-701, 1999

26. Mori K, Murata T, Hashimoto N, Handa H: Clinical analysis of arteriovenous malformations in children. Childs Brain 6:13-25, 1980

27. Nataf F, Schlienger M, Lefkopoulos D, Merienne L, Ghossoub M, Foulquier JN, Deniaud-Alexandre E, Mammar H, Meder JF, Turak B, Huart J, Touboul E, Roux FX: Radiosurgery of cerebral arteriovenous malformations in children: A series of 57 cases. Int J Radiat Oncol Biol Phys 57: 184 -195, 2003

28. Nicolato A, Lupidi F, Sandri MF, Foroni R, Zampieri P, Mazza C, Maluta S, Beltramello A, Gerosa M: Gamma knife radiosurgery for cerebral arteriovenous malformations in children/ adolescents and adults. Part I: Differences in epidemiologic, morphologic, and clinical characteristics, permanent complications, and bleeding in the latency period. Int J Radiat Oncol Biol Phys 64(3):904-913, 2005

29. Ogilvy CS, Stieg PE, Awad I, Brown RD Jr, Kondziolka D, Rosenwasser R, Young WL, Hademenos G: AHA Scientific Statement: Recommendations for the management of intracranial arteriovenous malformations: A statement for healthcare professionals from a special writing group of the Stroke Council, American Stroke Association. Stroke 32:14581471, 2001

30. Paulsen RD, Steinberg GK, Norbash AM, Marcellus ML, Marks MP: Embolization of basal ganglia and thalamic arteriovenous malformations. Neurosurgery 44:991-997, 1999

31. Pollock BE, Flickinger JC, Lunsford LD, Bissonette DJ, Kondziolka D: Factors that predict the bleeding risk of cerebral arteriovenous malformations. Stroke 27:1-6, 1996

32. Pollock BE, Flickinger CJ: A proposed radiosurgery-based grading system for arteriovenous malformations. J Neurosurg 96:79-85, 2002

33. Pollock BE, Gorman DA, Coffey RJ: Patient outcomes after arteriovenous malformation radiosurgical management: Results based on a 5-14-year follow-up study. Neurosurgery 52(6):1296-1297, 2003
34. Pollock BE, Flickinger JC: Modification of the radiosurgerybased arteriovenous malformation grading system. Neurosurgery 63:239-243, 2008

35. Pollock BE: Arteriovenous malformation radiosurgery: Now you see it, now you don't. World Neurosurgery 77(2): 267-268, 2012

36. Pollock BE, Flickinger JC, Lunsford LD, Bissonette DJ, Kondziolka D: Hemorrhage risk after stereotactic radiosurgery of cerebral arteriovenous malformations. Neurosurgery 38(4):652-661, 1996

37. Pollock BE, Flickinger JC, Lunsford LD, Maitz A, Kondziolka D: Factors associated with successful arteriovenous malformation radiosurgery. Neurosurgery 42:1239-1247, 1998

38. Schaller C, Schramm J: Microsurgical results for small arteriovenous malformations accessible for radiosurgical or embolization treatment. Neurosurgery 40:664-674, 1997

39. Spetzler RF, Martin NA: A proposed grading system for arteriovenous malformations. J Neurosurg 65:476-483, 1986

40. Steiner L, Lindquist C, Steiner M: Stereotactic radiosurgery Part 1: Radiosurgery with focused gamma-beam irradiation in children. In: Edwards MS, Hoffman HJ, (eds). Cerebral Vascular Disease in Children and Adolescents. Baltimore: Williams \& Wilkins, 1989: 367-388

41. Sun DQ, Carson KA, Raza SM, Batra S, Kleinberg LR, Lim $M$, Huang J, Rigamonti D: The radiosurgical treatment of arteriovenous malformations: Obliteration, morbidities, and performance status. Int J Radiat Oncol Biol Phys 80(2):354361, 2011

42. Zabel-du Bois A, Milker-Zabel S, Huber P, Schlegel W, Debus $\mathrm{J}$ : Risk of hemorrhage and obliteration rates of LINAC based radiosurgery for cerebral arteriovenous malformations treated after prior partial embolization. Int J Radiat Oncol Biol Phys 68(4):999-1003, 2007

43. Zabel A, Milker-Zabel S, Huber P, Schulz-Ertner D, Schlegel W, Debus J: Treatment outcome after linac-based radiosurgery in cerebral arteriovenous malformations: Retrospective analysis of factors affecting obliteration. Radiother Oncol 77(1):105110, 2005 